\title{
Online wine purchasing: a comparison between South Africa and Italy
}

Nicola Cobelli

Department of Business Administration, The University of Verona, Verona, Italy, and

Georgina Wilkinson

Vinifera Program, Montpellier SupAgro, Montpellier, Languedoc-Roussillon, France

Received 18 October 2019 Revised 13 December 2019 Accepted 17 December 2019

\begin{abstract}
Purpose - The purpose of this study is to explore South African and Italian consumers' attitude toward online wine purchasing. In detail, through the application of the technology acceptance model (TAM), this research intends to explain the antecedents of consumers actual online purchasing of wine in South Africa and Italy. Design/methodology/approach - Two questionnaire-based surveys were conducted, yielding a sample of 190 consumers in South Africa and 179 in Italy. Data were analyzed through several techniques including $t$ tests, principal component factor analyses, and binary logistic regressions.

Findings - Overall, the findings show that South African and Italian online wine consumers are more similar than the offline wine consumers. However, perceived usefulness has an impact on the use of the online channel to purchase wine in Italy but not in South Africa, whereas perceived complexity has an effect in South Africa but not in Italy.

Research limitations/implications - This study adopts a convenience sampling technique, suggesting that the used samples are not representative of the whole population. Moreover, TAM offers a simple and clear understanding of the actual use of wine e-commerce but overlooks other potential explanatory factors.

Practical implications - Targeting online wine consumers in South Africa and Italy opens up the opportunity for using cross-national highly standardized product and communication strategies. However, different approaches are required to convert offline wine consumers to online wine consumers in South Africa and Italy.

Originality/value - This is the first cross-national study investigating consumers' attitude toward online wine purchasing in South Africa and Italy. Moreover, it offers a comparison of online and offline wine consumers in the two countries. In addition, the research offers a new point of view over consumers of Italy and South Africa, two important countries in terms of wine production and consumption that can be very beneficial for wineries owners and managers.
\end{abstract}

Keywords e-commerce, Wine, South Africa, Italy, Wine marketing, Industry 4.0, Online purchasing

Paper type Research paper

\section{Introduction}

Wine producers are increasingly adopting direct-to-consumer distribution channels, ranging from wine tasting room sales, wine clubs, and online sales (Higgins et al., 2015). In particular, wine e-commerce is becoming increasingly popular as the consumer can easily access information about wine through the web (Barber et al., 2006), and wine producers have the opportunity to expand into markets that may be unreachable otherwise (Higgins et al., 2015; Limayem et al., 2000). However, the adoption of wine online purchasing by consumers is still limited and it is not clear whether the importance of the purchasing drivers may vary between online and offline wine consumers.

(C) Nicola Cobelli and Georgina Wilkinson. Published by Emerald Publishing Limited. This article is published under the Creative Commons Attribution (CC BY 4.0) licence. Anyone may reproduce, distribute, translate and create derivative works of this article (for both commercial and non-commercial purposes), subject to full attribution to the original publication and authors. The full terms of this licence may be seen at http://creativecommons.org/licences/by/4.0/legalcode

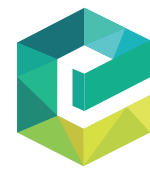

The TQM Journal

Vol. 32 No. 4,2020 pp. $837-847$

Emerald Publishing Limited DOI 10.1108/TQM-10-2019-0242 
TQM

32,4

838

Available studies show that, in general, the trends of drinking wine have changed (Ajami et al., 2018), and it is therefore hugely important for wine companies and producers to understand their consumers purchasing processes, which may also vary depending on the culture and country of consumers (Balestrini and Gamble, 2006). Overall, available knowledge has emphasized the difficulty in determining the purchase drivers of wine and understanding wine consumer behavior with the many factors influencing the final decision (Balestrini and Gamble, 2006; Corduas et al., 2013; Galloway et al., 2008; Goodman, 2009; Hollebeek et al., 2007; Keown and Casey, 1995; Lockshin Corsi, 2012). More interestingly, previous research has shown that there is a difference in primary decisions and choices (Brown, 2013) made at the point of sale due to these different influential cues (Chaney, 2000; Herbst and Von Arnim, 2009; Mueller and Szolnoki, 2010). In particular, in cases where the wine cannot be tasted before purchase, the basic value will be assumed by evaluating additional value features (Mueller and Szolnoki, 2010; Cassia et al., 2015).

Drawing on these premises, the aim of this study is to determine the differences in consumer perception, behavior, and attitude toward online wine purchasing focusing on the cross-cultural comparison of South African and Italian consumers. In detail, we explore both the antecedents of the adoption of online wine purchasing and the importance of the purchasing drivers in the two countries. The results of this study will not only advance scientific knowledge on wine e-commerce but it will also assist wine producers to address online wine consumers in the two countries.

\section{Literature review and hypotheses}

The occurrence of the direct channels linking producers and consumers increased greatly with the increase in Internet usage. As the transactions are directly with the consumer, e-commerce is the most prominent method for connecting and communicating with the consumer, introducing them to new products as well as conducting the sale (Jiang et al., 2016). With technology and the internet growing at a rapid pace throughout the world, information is readily available and accessible immediately (Yen, 2014). However, using e-commerce in the wine industry differs greatly depending on the target market, the country, and the company size (Begalli et al., 2009).

A study conducted by Alonso et al. (2013) on wineries in Australia, Canada, New Zealand, Spain, Italy, South Africa, and the US and their use of social media, highlighted that 35 percent of the wineries use social media to communicate with customers as the primary reason. Events at the winery and promotions of their wines were mainly communicated. When looking specifically at Facebook, a study conducted in Australia by Dolan et al. (2016) found that an effective social media strategy is important especially for wine brands. Understanding the customers and how they might engage with the posts as well as scheduling when is the best time for a post is crucial. It was found that photos generally received the most engagement in regards to likes, comments, and shares compared to text status updates or videos. Slightly more engagement was found on Wednesdays and Fridays, more specifically between 8 a.m. and 10 a.m. and then 4 p.m. and 9 p.m. (Dolan et al., 2016). Nonetheless, despite remarkable customer engagement, many customers resist the adoption of online wine purchasing. In fact, online wine purchasing represents about five percent of the total wine market. Although this percentage is small, it is slowly increasing, and in some areas, it is much higher (Higgins et al., 2015; Lockshin Corsi, 2012).

When looking at the general profile of online shoppers, the typical behavior is the purchase of wines with higher prices, and these online buyers consider themselves knowledgeable about wine and are more interested in finding out more information about what they are purchasing (Alreck and Settle, 2002; Higgins et al., 2015).

Although South Africans are starting to embrace the online culture, many wineries are behind in regards to technology (Kirkby, 2014). The major aspect lacking in winery websites 
is the mobile-friendly property which is very important with much of online research being done on mobile phones (Kirkby, 2014). According to previous research, South Africans have not been enthusiastic online shoppers because of the physical touch of the product. In addition, the taste and aroma of the wine itself is generally important to the consumer when making the final purchasing decision (Kirkby, 2014). There is a trend that first time customers generally purchase one or two bottles with a lower value and as their confidence grows, more bottles of higher values are purchased (Kirkby, 2014).

A study conducted in a wine producing region in the northeast of Italy by Begalli et al. (2009) had some interesting results when researching e-commerce and the involvement of the wineries. It was found that only 7.4 percent of the wineries in the sample were involved in e-commerce, and many of the wineries were using the websites as more of an online brochure. The region is made up of many small wineries, and this could be a main reason why there is so little involvement as it may not be feasible on the small scale of most of these wineries. The main hurdle in adopting e-commerce in this Italian wine region seemed to come down to the mentality of the producer and the unwillingness to look at change and using new technology in the sale of their products. Although many of these wineries have established websites that generally includes most wineries in Italy, they have not come to understand how to use their website to its full potential as a dominant commercial tool. More interestingly, the low adoption of the e-commerce also seems to be greatly related to customer resistance in purchasing wine online (Begalli et al., 2009).

The technology acceptance model (TAM) has been widely used to explain customer adoption of new technologies. The TAM suggests that the user's intention to accept new technology is based on user assessments of the usefulness and complexity of the technology (Davis, 1989; Fishbein and Ajzen, 1975; Lee et al., 2005; Qiu and Li, 2008). In detail, the user's intention to adopt new technology is positively influenced by its perceived usefulness whereas perceived complexity exerts a negative effect. TAM has been used in several settings due to its precision and conciseness. In particular, its effectiveness has been established by numerous empirical studies also in the wine industry (Notta and Vlachvei, 2013; Sheridan et al., 2008). For the purpose of this study, we are interested in applying the TAM to both the South African and the Italian sample to explain consumer adoption of online wine purchasing. As shown by Kahneman (2011), factors such as customer experience may cause different and sometimes biased perceptions of the benefits and complexity required to adopt a new product or technology. Therefore, we suggest that South African and Italian consumers may have developed different perceptions related to both the usefulness and the complexity of purchasing wine online. However, as no previous research is available on this point, we developed the following general hypotheses stating that both in South Africa and Italy:

H1. Perceived usefulness of wine e-commerce is a positive antecedent of actual wine e-commerce usage.

H2. Perceived complexity of wine e-commerce is a negative antecedent of actual wine e-commerce usage.

\section{Research methods}

Research context: the South African and Italian wine markets

The South African wine industry has been progressing since the 1600s when the first vineyards were harvested in 1659 by the Huguenot settlers (SAWIS, 2016). Therefore, the South African wine industry is relatively young in comparison to the Italian wine industry which existed before Christ (BC) (Phillips, 2001). When looking into the details of the South African and Italian wine markets and consumers, there are immediate differences in culture, lifestyle, and values. The annual per capita consumption of wine in South Africa was 7.73 
TQM

32,4

840

liters in 2016 whereas the domestic per capita consumption in Italy was 37.5 liters (Mason et al., 2015; SAWIS, 2016). South Africa is a hugely diverse country with 11 official languages and many prominent cultures with a strong history that has had a huge impact on the present lifestyles. The population is made up of four ethnic groups: Black African (80.2 percent), Colored (8.8 percent), White (8.4 percent), and Indian/Asian (2.5 percent) which adds great diversity to the South African population (Statistics South Africa, 2014). In South Africa, wine constitutes 18 percent of the alcohol beverage market, whereas beer makes up 56 percent and spirits make up the balance (SAWIS, 2016). Culturally, the majority of the South African population, being Black Africans, prefers beer and spirits as opposed to wine (Ngwako et al., 2007). On the contrary, in the Italian culture, wine is considered by far the most important source of alcohol accounting for 66 percent of the pure alcohol per capita with beer accounting for only 23 percent (MarketLine, 2015a). In South Africa, throughout the apartheid era, nonessentials such as wine were unaffordable by the majority of the suppressed nonwhite population who were less affluent (Ngwako et al., 2007). Many nonwhite laborers working in wineries were paid using the 'tot' system which was part payment of wages in low quality wine and with this payment, a spike in alcoholism occurred among these communities (Ngwako et al., 2007). In addition, with alcohol being very difficult to purchase and sell legally for nonwhite South Africans during apartheid, it was common to consume alcohol that had been home brewed. This resulted in alcohol-related health issues and had a negative bearing on social and family life, hence the negative perception and low interest in wine by nonwhite consumers (Ngwako et al., 2007).

The South African wine industry is producing 900 million liters of wine annually. More than half of these volumes are exported around the world, and the balance is sold on the domestic wine market (SAWIS, 2016). Although wine only constitutes a small percentage of the pure alcohol per capita, the final value of the South African wine market was valued at USD \$ 3,187 million in 2014 (MarketLine, 2015b; Ndanga et al., 2010). Italy differs hugely as it is one of the biggest wine producing countries in Europe, making up 19.8 percent of the total European wine market value and also one of the biggest wine markets globally with final volumes of 2,670 million liters in 2014. When comparing the sizes of these two unique wine markets, the Italian wine market is much larger than the South African one in regards to revenue. In 2014, the final value of the Italian wine market was USD\$34,221 million, over 10 times the value of the South African market (Allamani et al., 2014; MarketLine 2015a).

\section{Data collection and analysis}

Two questionnaire-based surveys were conducted, one among South African consumers and one among Italian consumers. The South African survey was conducted in English as this is the common language spoken in South Africa. The survey conducted on the Italian consumers was translated into Italian to ensure better understanding of the questions and to reach as many Italian consumers as possible. Two pretests, one in South Africa and one in Italy, were conducted on the survey by 10 participants with the intention of receiving feedback with any difficulties or misunderstandings they encountered in the process of answering the survey. These consumers whom had one week to answer the survey submitted feedback via e-mail. This resulted in the rephrasing of a few questions and changing the wording of any misleading points.

The final questionnaire included multiple questions related to the respondents' profiles and wine purchasing and drinking habits. These questions were related to the average number of glasses consumed per week, knowledge and experience with wine, place where wine is mainly consumed, purchase channels of wine consumed at home, and the importance of several purchasing factors (for example taste, price, and region of origin). In regard to wine e-commerce, respondents were required to state the frequency with which they purchase wine online (never, sometimes, often, and always) and their level of 
agreement with five statements about purchasing wine online. The first three statements (is convenient, offers better value for money, and is time efficient) were intended to grasp perceived usefulness, whereas the last two (it is difficult to differentiate products without physically seeing them and I like to see the product before paying for it) were used to measure perceived complexity.

The link to the online questionnaire was distributed online through the personal networks of the authors. Overall, 245 and 333 responses were obtained from South African and Italian consumers, respectively. For the purpose of our analysis, we only considered fully completed questionnaires done by respondents meeting two criteria: a) consuming at least one glass of wine per week and b) consuming wine at least sometimes at home. This procedure was intended to provide a sample of consumers with sufficient experience with wine and potentially interested in purchasing wine online. The final sample was composed by 190 South African consumers and 179 Italian consumers. The profiles of both samples are shown in Table I. Respondents were then divided into online and offline consumers. Respondents who sometimes, often, or always purchase wine online (Table II) were considered 'online consumers' whereas the remaining respondents were categorized as 'offline consumers.' In South Africa and Italy, online consumers were 65 and 26, respectively, whereas offline consumers were 125 and 153, respectively.

Data were analyzed through several techniques. We used a series of $t$-tests to compare South African and Italian online and offline consumers' perceptions of factors influencing wine purchasing. To test the research model, we first ran two principal component factor analyses, one for the South African sample and one for the Italian sample. This was done to determine the discriminant and convergent validity of perceived usefulness and perceived complexity. We then performed two binary logistic regressions (Menard, 2002), one for each of the two samples, with the dichotomous dependent variable being the respondents actual usage (yes/no) of e-commerce to purchase wine.

\begin{tabular}{llrr}
\hline Dimension & Items & $\begin{array}{r}\text { South Africa } \\
(n=190)\end{array}$ & \multicolumn{1}{c}{$\begin{array}{c}\text { Italy } \\
(n=179)\end{array}$} \\
\hline \multirow{2}{*}{ Gender } & $\mathrm{F}$ & $103(54.2 \%)$ & $113(63.1 \%)$ \\
& $\mathrm{M}$ & $87(45.8 \%)$ & $66(36.9 \%)$ \\
Age & $<25$ & $27(14.2 \%)$ & $64(35.7 \%)$ \\
& $26-35$ & $18(9.5 \%)$ & $52(29.0 \%)$ \\
& $36-45$ & $39(20.5 \%)$ & $35(19.6 \%)$ \\
& $46-55$ & $54(28.4 \%)$ & $20(11.2 \%)$ \\
Education level & $>55$ & $52(27.4 \%)$ & $8(4.5 \%)$ \\
& High school & $31(16.3 \%)$ & $80(44.7 \%)$ \\
& Bachelor's degree & $87(45.8 \%)$ & $52(29.0 \%)$ \\
Occupation & Master's degree & $38(20.0 \%)$ & $29(16.2 \%)$ \\
& Doctoral & $34(17.9 \%)$ & $18(10.1 \%)$ \\
& Retired & $21(11.0 \%)$ & $3(1.7 \%)$ \\
Average number of glasses consumed & $158(83.2 \%)$ & $121(67.6 \%)$ \\
per week & Employed & $11(5.8 \%)$ & $55(30.7 \%)$ \\
& Unemployed (including & & \\
& students) & $23(12.1 \%)$ & $48(26.8 \%)$ \\
& $1-2$ & $39(20.5 \%)$ & $51(28.5 \%)$ \\
& $3-4$ & $32(16.8 \%)$ & $29(16.2 \%)$ \\
& $5-6$ & $29(15.3 \%)$ & $20(11.2 \%)$ \\
& $7-8$ & $25(13.2 \%)$ & $10(5.6 \%)$ \\
& $9-10$ & $10(5.3 \%)$ & $7(3.9 \%)$ \\
& $11-12$ & $8(4.2 \%)$ & $5(2.8 \%)$ \\
& $>14-14$ & $24(12.6 \%)$ & $9(5.0 \%)$
\end{tabular}

Online wine purchasing 
TQM

32,4

\section{2}

Table II.

Channels through which respondents purchase wine consumed at home

\section{Research results}

The analysis of the factors influencing wine purchasing, reveals that the differences between the South African and the Italian consumers are less numerous in the case of online consumers than in the case of offline consumers (Table III). Online consumers differ in regards to three factors influencing their wine purchase decision: the importance of the appearance of bottle is higher in South Africa than that in Italy $\left(X_{\text {South Africa }}=3.09\right.$, $\left.X_{\text {Italy }}=2.58 ; t(2,89)=2.12, p<0.05\right)$, whereas the importance of the region of origin $\left(X_{\text {South Africa }}=3.02, X_{\text {Italy }}=3.62 ; t(2,89)=-2.13, p<0.05\right)$, and the production through sustainable practices $\left(X_{\text {South Africa }}=2.91, X_{\text {Italy }}=3.62 ; t(2,89)=-2.64, p<0.05\right)$ are greater in Italy than in South Africa. When considering offline consumers, three additional differences emerged from the analysis. In detail, price is more important in South Africa than in Italy $\left(X_{\text {South Africa }}=3.49, X_{\text {Italy }}=3.25 ; t(2,276)=1.80, p<0.10\right)$, whereas aroma $\left(X_{\text {South Africa }}=3.49, X_{\text {Italy }}=3.76 ; t(2,276)=-1.88, p<0.10\right)$ and the impression on others made by the consumer's selection $\left(X_{\text {South Africa }}=2.26, X_{\text {Italy }}=2.90 ; t(2,276)=-4.75\right.$,

\begin{tabular}{|c|c|c|c|c|c|c|c|c|}
\hline \multirow[b]{2}{*}{ Channel } & \multicolumn{4}{|c|}{$\begin{array}{c}\text { Italy } \\
\text { Frequency }(n=179)\end{array}$} & \multicolumn{4}{|c|}{$\begin{array}{c}\text { South Africa } \\
\text { Frequency }(n=190)\end{array}$} \\
\hline & Never & Sometimes & Often & Always & Never & Sometimes & Often & Always \\
\hline Online & 153 & 14 & 11 & 1 & 125 & 46 & 16 & 3 \\
\hline Wine shops & 40 & 87 & 40 & 12 & 33 & 99 & 49 & 9 \\
\hline Bottle/Liquor stores & 129 & 44 & 5 & 1 & 5 & 60 & 104 & 21 \\
\hline Supermarkets & 44 & 64 & 54 & 17 & 20 & 58 & 92 & 20 \\
\hline
\end{tabular}

\begin{tabular}{|c|c|c|c|c|c|c|c|c|}
\hline \multirow[b]{2}{*}{ Purchasing factor } & \multirow{2}{*}{$\begin{array}{l}\text { Purchasing } \\
\text { online }\end{array}$} & \multicolumn{3}{|c|}{ South Africa } & \multicolumn{3}{|c|}{ Italy } & \multirow{2}{*}{$\begin{array}{l}\text { South Africa } \\
\text { vs. Italy } \\
t \text {-statistic }\end{array}$} \\
\hline & & $n$ & Mean & Std. dev. & $N$ & Mean & Std. dev. & \\
\hline \multirow[t]{2}{*}{ Taste } & No & 125 & 4.26 & 1.39 & 153 & 4.10 & 1.38 & 0.99 \\
\hline & Yes & 65 & 4.34 & 1.38 & 26 & 4.23 & 1.37 & 0.33 \\
\hline \multirow[t]{2}{*}{ Price } & No & 125 & 3.49 & 1.14 & 153 & 3.25 & 1.07 & $1.80 *$ \\
\hline & Yes & 65 & 3.40 & 1.03 & 26 & 3.12 & 0.82 & 1.39 \\
\hline \multirow[t]{2}{*}{ Brand } & No & 125 & 2.90 & 1.07 & 153 & 2.77 & 1.10 & 1.01 \\
\hline & Yes & 65 & 2.80 & 1.00 & 26 & 2.46 & 1.17 & 1.29 \\
\hline \multirow[t]{2}{*}{ Aroma } & No & 125 & 3.49 & 1.14 & 153 & 3.76 & 1.24 & $-1.88^{*}$ \\
\hline & Yes & 65 & 3.68 & 1.09 & 26 & 3.85 & 1.16 & -0.64 \\
\hline \multirow[t]{2}{*}{ Region of origin } & No & 125 & 2.74 & 1.19 & 153 & 3.46 & 1.22 & $-5.00 * * *$ \\
\hline & Yes & 65 & 3.02 & 1.14 & 26 & 3.62 & 1.24 & $-2.13 * *$ \\
\hline \multirow[t]{2}{*}{ Variety } & No & 125 & 3.24 & 1.12 & 153 & 3.05 & 1.03 & 1.50 \\
\hline & Yes & 65 & 3.34 & 1.06 & 26 & 3.19 & 1.10 & 0.57 \\
\hline Description on the & No & 125 & 2.84 & 1.02 & 153 & 2.90 & 1.07 & -0.49 \\
\hline label & Yes & 65 & 2.91 & 1.03 & 25 & 2.60 & 1.15 & 1.16 \\
\hline Appearance of the & No & 125 & 3.07 & 1.06 & 153 & 2.82 & 1.18 & $1.83^{*}$ \\
\hline bottle & Yes & 65 & 3.09 & 1.00 & 26 & 2.58 & 1.06 & $2.12^{* * *}$ \\
\hline Wine produced & No & 125 & 2.80 & 1.06 & 153 & 3.06 & 1.17 & $-1.91^{*}$ \\
\hline $\begin{array}{l}\text { through sustainable } \\
\text { practices }\end{array}$ & Yes & 65 & 2.91 & 1.01 & 26 & 3.62 & 1.20 & $-2.64^{* *}$ \\
\hline How impressed & No & 125 & 2.26 & 1.14 & 153 & 2.90 & 1.12 & $-4.75^{* * * *}$ \\
\hline others will be by my & Yes & 65 & 2.42 & 1.30 & 26 & 2.50 & 1.14 & -0.30 \\
\hline
\end{tabular}

Table III.

The importance of purchasing factors for offline and online consumers in South Africa and Italy (1 = completely unimportant and $5=$ very important)

\section{selection}

Notes: $* p<0.1 ; * * p<0.05 ; * * * p<0.01$ 

$p>0.10$ ). On the contrary for the Italian sample, perceived usefulness is a significant positive

\begin{tabular}{|c|c|c|c|c|c|}
\hline & \multicolumn{2}{|c|}{ South Africa } & \multicolumn{2}{|c|}{ Italy } & \\
\hline & Factor 1 & Factor 2 & Factor 1 & Factor 2 & \\
\hline \multicolumn{6}{|l|}{ Perceived usefulness } \\
\hline Better value for money & 0.792 & -0.040 & 0.835 & -0.083 & \\
\hline Time efficient & 0.749 & 0.009 & 0.560 & 0.190 & \\
\hline Convenient & 0.687 & -0.033 & 0.715 & -0.327 & \\
\hline $\begin{array}{l}\text { Perceived complexity } \\
\text { Difficult to differentiate products without } \\
\text { physically seeing them }\end{array}$ & -0.021 & 0.894 & 0.194 & 0.872 & $\begin{array}{r}\text { Exploratory factor } \\
\text { analysis with principal } \\
\text { components, }\end{array}$ \\
\hline $\begin{array}{l}\text { Like to see product before paying for it } \\
\% \text { of variance explained }\end{array}$ & $\begin{array}{l}-0.031 \\
34.56\end{array}$ & $\begin{array}{l}0.893 \\
30.63\end{array}$ & $\begin{array}{l}-0.322 \\
38.75\end{array}$ & $\begin{array}{l}0.839 \\
26.81\end{array}$ & $\begin{array}{r}\text { extraction, and } \\
\text { varimax rotation }\end{array}$ \\
\hline
\end{tabular}

\begin{tabular}{|c|c|c|c|c|c|}
\hline & \multicolumn{2}{|c|}{ South Africa } & Italy & $\operatorname{Exp}(b)$ & \\
\hline Perceived usefulness & 0.251 & 1.285 & $0.465^{* *}$ & 1.592 & \\
\hline Perceived complexity & $-0.404^{* *}$ & 0.668 & -0.133 & 0.875 & \\
\hline Constant & $0.687 * * *$ & 1.989 & $1.852^{* * * *}$ & 6.371 & \\
\hline \multicolumn{6}{|l|}{ Model fit } \\
\hline Cox and Snell (1989) $R 2$ & 0.047 & & 0.027 & & \\
\hline Nagelkerke (1991) $R 2$ & 0.064 & & 0.047 & & \\
\hline \multicolumn{6}{|c|}{ Hosmer and Lemeshow (1989) test } \\
\hline Chi-square & 6.35 & & 6.57 & & \\
\hline Df & 8 & & 8 & & \\
\hline Sig. & 0.60 & & 0.58 & & \\
\hline Overall hit ratio (\%) & 67.4 & & 85.5 & & \\
\hline \multicolumn{5}{|c|}{$\begin{array}{l}\text { Notes: } * p<0.1 ; * * p<0.05 ; * * * p<0.01 \text {; Dependent variable: respondent's actual usage vs. nonusage of } \\
\text { e-commerce to purchase wine. }\end{array}$} & $\begin{array}{r}\text { Results of binary } \\
\text { logistic regression }\end{array}$ \\
\hline
\end{tabular}

Notes: $* p<0.1 ; * *<<0.05$; $* * * p<0.01$; Dependent variable: respondent's actual usage vs. nonusage of e-commerce to purchase wine. $p<0.01)$ are more important in Italy than in South Africa. Therefore, although South African and Italian offline consumers show relevant differences along major factors such as price and aroma, South African and Italian online consumers are more similar.

Before testing the suggested hypotheses, two factor analyses (one for the South African sample and one for the Italian sample) were conducted to assess whether the five statements about purchasing wine online loaded on the two intended concepts (perceived usefulness and perceived complexity). The results (Table IV) confirmed that perceived usefulness and perceived complexity were two distinct concepts for both samples and that the results were as expected.

Perceived usefulness and perceived complexity were then entered as the dependent variables of two binary logistic regressions (one for the South African sample and one for the Italian sample) with a respondent's actual usage versus nonusage of e-commerce as the dependent variables. Both models fit the data reasonably well as highlighted by the resulting ratios, 67.4 percent for the South African sample and 85.5 percent for the Italian sample (Table V). Regarding the hypotheses testing, the models' estimation shows different findings for the two samples. For the South African sample, perceived complexity is a significant, negative predictor of a respondent's use of wine e-commerce $(b=-0.404 ; \operatorname{Exp}(b)=0.668$; $p<0.05)$ whereas perceived usefulness has no significant effect $(b=0.251 ; \operatorname{Exp}(b)=1.285$; antecedent of a respondent's use of wine e-commerce $(b=0.465 ; \operatorname{Exp}(b)=1.592 ; p<0.05)$

\section{Online wine purchasing}

Perceived usefulness

Better value for money

Convenient

0.749

0.009

0.835

$-0.083$

0.190

Perceived complexity

physically seeing them

$\%$ of variance explained

0.893

$-0.32$

0.872

Exploratory factor components, varimax rotation 
TQM

32,4

\section{$844 \quad$ Conclusions}

The purpose of this study was to explore South African and Italian consumers' attitude toward purchasing wine online and to understand the antecedents of their actual usage of wine e-commerce. Two questionnaire-based surveys were conducted, yielding a sample of 190 consumers in South Africa and 179 in Italy. Several techniques including $t$-tests, principal component factor analyses, and binary logistic regressions were used to analyze the data. From the data analyses, the perception of usefulness and complexity of wine e-commerce was looked at to develop two hypotheses for both South African and Italian consumers.

\section{Practical implications}

The findings suggest that South African and Italian online wine consumers are more similar than the offline wine consumers. Therefore, although firms selling wine through offline channels in South Africa and Italy may be required to introduce significant adaptations in their offerings to meet the demand of local consumers. The online channels open up the opportunity for cross-national highly standardized product and communication strategies (Szymanski et al., 1993). It should however be noted that South African and Italian online wine consumers are not perfect global consumers (Harrison-Walker, 2002) and that some adaptations to the local demand may be needed.

This study also offers useful insight about suitable strategies to convert offline wine consumers to online wine consumers. With this in mind, wine producers need to develop completely different strategies in South Africa and Italy. Both offline and online South African wine consumers are aware of the benefits provided by wine e-commerce, such as convenience, better value for money, and time efficiency. However, these offline consumers also perceive high complexity in purchasing wine online as well as concern of not being able to see and taste the product before purchase when choosing from an array of wines. Therefore, wine producers should reduce such a high level of uncertainty. For example, they could establish a multichannel strategy to offer both the opportunity for the consumers to see and taste the wine offline such as attending specific events and then promote the purchase of the wine online. On the contrary, both online and offline Italian wine consumers are not afraid of the complexity of purchasing wine online. However, offline Italian wine consumers cannot recognize the benefits of using online channels. Therefore, wine producers interested in expanding their online sales in Italy should emphasize the additional benefits offered by this channel such as providing specific services to online wine purchasers only.

\section{Limitations and future research recommendations}

When interpreting the results of this research, several limitations should be mentioned. First, this study adopted a convenience sampling technique, suggesting that the used samples are not representative of the whole population. Future studies involving larger samples, based on more sophisticated sampling techniques, may provide further and stronger evidence. In addition, the number of online wine consumers involved in this study is limited. This limitation is, to a large extent, the result of the low percentage of consumers currently purchasing wine online. However, through the cooperation with wine e-commerce websites, researcher may be able to recruit a higher number on online consumers. It would also be 
interesting to investigate whether consumers' attitudes differ when purchasing wine through a winery's website or through e-commerce platforms such as Alibaba.com. Finally, although the TAM offers the opportunity of parsimony, new studies may enrich the understanding of consumers' attitude toward purchasing wine online by adding other independent and moderating variables.

In spite of the mentioned limitations, this work enables wineries owners and managers to analyze eventual weaknesses and threads, along with opportunities and strengths in their organization.

\section{References}

Ajami, M.P., Navarro Elola, L. and Pastor, J. (2018), "Validation and improvement of the European customer satisfaction index for the Spanish wine sector", The TQM Journal, Vol. 30 No. 2, pp. 133-152.

Allamani, A., Voller, F., Pepe, P., Baccini, M., Massini, G. and Cipriani, F. (2014), "Italy between drinking culture and control policies for alcoholic beverages", Substance Use and Misuse, Vol. 49 No. 12, pp. 1646-1664.

Alonso, A.D., Bressan, A., O'Shea, M. and Krajsic, V. (2013), "Website and social media usage: implications for the further development of wine tourism, hospitality, and the wine sector", Tourism Planning and Development, Vol. 10 No. 3, pp. 229-248.

Alreck, P. and Settle, R.B. (2002), "Gender effects on Internet, catalogue and store shopping”, Journal of Database Marketing and Customer Strategy Management, Vol. 9 No. 2, pp. 150-162.

Balestrini, P. and Gamble, P. (2006), "Country-of-origin effects on Chinese wine consumers", British Food Journal, Vol. 108 No. 5, pp. 396-412.

Barber, N., Almanza, B.A. and Donovan, J.R. (2006), "Motivational factors of gender, income and age on selecting a bottle of wine", International Journal of Wine Marketing, Vol. 18 No. 3, pp. 218-232.

Begalli, D., Codurri, S. and Gaeta, D. (2009), "Wine and web marketing strategies: the case study of Italian speciality wineries", British Food Journal, Vol. 111 No. 6, pp. 598-619.

Brown, A. (2013), "Quality: where have we come from and what can we expect?", The TQM Journal, Vol. 25 No. 6, pp. 585-596.

Cassia, F., Ugolini, M.M., Cobelli, N. and Gill, L. (2015), "Service-based vs. goods-based positioning of the product concept: effects on customer perceived value", The TQM Journal, Vol. 27 No. 2, pp. 247-255.

Chaney, I.M. (2000), "External search effort for wine", International Journal of Wine Marketing, Vol. 12 No. 2, pp. 5-21.

Corduas, M., Cinquanta, L. and Ievoli, C. (2013), "The importance of wine attributes for purchase decisions: a study of Italian consumers' perception”, Food Quality and Preference, Vol. 28 No. 2, pp. 407-418.

Cox, D.R. and Snell, E.J. (1989), Analysis of Binary Data, 2nd ed., Chapman and Hall, London.

Davis, F.D. (1989), "Perceived usefulness, perceived ease of use, and user acceptance of information technology", MIS Quarterly, Vol. 13 No. 3, pp. 319-340.

Dolan, R., Conduit, J., Fahy, J. and Goodman, S. (2016), "Facebook for wine brands: an analysis of strategies for Facebook posts and user engagement actions", Proceedings of the 9th AWBR International Conference, 17-18 February, University of South Australia, Adelaide, Australia, pp. 457-465.

Fishbein, M. and Ajzen, I. (1975), Belief, Attitude, Intention and Behavior: An Introduction to Theory and Research, Addison-Wesley, Reading, MA.

Galloway, G., Mitchell, R., Getz, D., Crouch, G. and Ong, B. (2008), "Sensation seeking and the prediction of attitudes and behaviours of wine tourists", Tourism Management, Vol. 29 No. 5, pp. 950-966. 
TQM 32,4

Goodman, S. (2009), "An international comparison of retail consumer wine choice", International Journal of Wine Business Research, Vol. 21 No. 1, pp. 41-49.

Harrison-Walker, L.J. (2002), "If you build it, will they come? Barriers to international e-marketing", Journal of Marketing Theory and Practice, Vol. 10 No. 2, pp. 12-21.

Herbst, F. and Von Arnim, C. (2009), "The role and influence of wine awards as perceived by the South African wine consumers", Acta Commercii, Vol. 9 No. 1, pp. 90-101.

Higgins, L.M., McGarry Wolf, M., Bitter, R. and Amspacher, W. (2015), "Winery distribution choices and the online wine buyer", Journal of Food Distribution Research, Vol. 46 No. 3, pp. 32-49.

Hollebeek, L.D., Jaeger, S.R., Brodie, R.J. and Balemi, A. (2007), "The influence of involvement on purchase intention for new world wine”, Food Quality and Preference, Vol. 18 No. 8, pp. 1033-1049.

Hosmer, D.W. and Lemeshow, S. (1989), Applied Logistic Regression, John Wiley \& Sons, New York.

Jiang, L., Jun, M. and Yang, Z. (2016), "Customer-perceived value and loyalty: how do key service quality dimensions matter in the context of B2C e-commerce?", Service Business, Vol. 10 No. 2, pp. 301-317.

Kahneman, D. (2011), Thinking, Fast and Slow, Farrar, Straus and Giroux, New York, NY.

Keown, C. and Casey, M. (1995), "Purchasing behaviour in the Northern Ireland wine market", British Food Journal, Vol. 97 No. 1, pp. 17-20.

Kirkby (2014), "Wine e-commerce. A growing, yet challenging phenomenon”, WineLand Magazine, retreived from: https://www.wineland.co.za/wine-e-commerce-a-growing-yet-challengingphenomenon (accessed October 18 2019).

Lee, M.K., Cheung, C.M. and Chen, Z. (2005), "Acceptance of Internet-based learning medium: the role of extrinsic and intrinsic motivation”, Information and Management, Vol. 42 No. 8, pp. 1095-1104.

Limayem, M., Khalifa, M. and Frini, A. (2000), "What makes consumers buy from Internet? A longitudinal study of online shopping", IEEE Transactions on Systems, Man, and CyberneticsPart A: Systems and Humans, Vol. 30 No. 4, pp. 421-432.

Lockshin, L. and Corsi, A.M. (2012), "Consumer behaviour for wine 2.0: a review since 2003 and future directions", Wine Economics and Policy, Vol. 1 No. 1, pp. 2-23.

MarketLine (2015a), Wine in Italy. MarketLine Industry Portfolio, retreived from: https:/store. marketline.com/report/mlohme7472-wine-in-italy (accessed October 18 2019).

MarketLine (2015b), Wine in South Africa. MarketLine Industry Portfolio, retreived from: https://store. marketline.com/report/mlohme7442-wine-in-south-africa (accessed October 18 2019).

Mason, M., Gos, L. and Moretti, A. (2015), “The wine sector in the digital era: an empirical evaluation of E-quality opportunities", Journal of Internet Banking and Commerce, Vol. 20 No. 3, p. 1.

Menard, S. (2002), Applied Logistic Regression Analysis, Sage, Thousand Oaks.

Mueller, S. and Szolnoki, G. (2010), "The relative influence of packaging, labelling, branding and sensory attributes on liking and purchase intent: consumers differ in their responsiveness", Food Quality and Preference, Vol. 21 No. 7, pp. 774-783.

Nagelkerke, N.J. (1991), "A note on a general definition of the coefficient of determination”, Biometrika, Vol. 78 No. 3, pp. 691-692.

Ndanga, L.Z., Louw, A. and Van Rooyen, J. (2010), "Increasing domestic consumption of South African wines: exploring the market potential of the "black diamonds"”, Agrekon, Vol. 49 No. 3, pp. 293-315.

Ngwako, S.M., Van Rooyen, J., Janssens, W., Bostyn, F. and D’Haese, L. (2007), "Exploring black economic empowerment in the South African wine industry: a case study", in International Food and Agribusiness Management Association, 18th Annual World Symposium, Parma, Italy, 2007. 
Notta, O. and Vlachvei, A. (2013), "Web Site utilization in SME business strategy: the case of Greek wine SMEs", World, Vol. 3 No. 5, pp. 131-141.

Phillips, R. (2001), A Short History of Wine, Ecco, New York.

Qiu, L. and Li, D. (2008), "Applying TAM in B2C E-commerce research: an extended model”, Tsinghua Science and Technology, Vol. 13 No. 3, pp. 265-272.

SAWIS (2016), "South African wine industry statistics NR4", available in November 2019 from: www. sawis.co.za.

Sheridan, M.J., Cazier, J.A. and May, D.B. (2008), "Leisure, wine and the internet: exploring the factors that impact the purchase of wine online", International Journal of Electronic Marketing and Retailing, Vol. 2 No. 3, pp. 284-297.

Statistics South Africa (2014), Mid-year Population Estimates, 2014, available in November 2019 from: https://www.statssa.gov.za/publications/P0302/P03022014.pdf.

Szymanski, D.M., Bharadwaj, S.G. and Varadarajan, P.R. (1993), "Standardization versus adaptation of international marketing strategy: an empirical investigation", The Journal of Marketing, Vol. 57 No. 4, pp. 1-17.

Yen, Y.S. (2014), "A comparison of quality satisfaction between transactional and relational customers in e-commerce”, The TQM Journal, Vol. 26 No. 6, pp. 577-593.

\section{Corresponding author}

Nicola Cobelli can be contacted at: nicola.cobelli@univr.it
Online wine purchasing

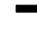

